\title{
Determination of upper mantle velocity structure using the $P$ and $S$ waves spectra
}

\author{
D. D. SINGH * \\ Received on August 2nd, 1982
}

\section{RIASSUNTO}

Si presenta uno studio per la determinazione della struttura superiore del mantello determinata dall'esame degli spettri delle onde $P$ ed $S$ per tre terremoti profondi avvenuti nel mare di Okhotsk e Hounshu in Giappone e registrati a Hyderabad (HYB) in India. Si è sviluppata una nuova procedura metodologica. Utilizzando una nuova finestra sui dati, si prendono le registrazioni delle componenti orizzontali e verticali per la durata approssimativa di 3-4 minuti e si determina la funzione di trasferimento crostale.

La nuova finestra ha come caratteristica quella di aumentare il segnale sopprimendo il rumore nell'intervallo desiderato di frequenza $0.02-0.18 \mathrm{~Hz}$. La funzione di trasferimento crostale ottenuta utilizzando la finestra, mostra un trend simile alla funzione di trasferimento ottenuta prendendo una durata del segnale di lunghezza minore - cioè quando il segnale risulta privo dell'arrivo di altre fasi come $P p, p P, P c P, P c S$, ecc.

Una durata maggiore dei segnali, 3-4 minuti, è sufficiente a fornire la struttura del mantello superiore fino ad una profondità di circa $400 \mathrm{~km}$. Le funzioni di trasferimento teoriche si sono ottenute usando la formulazione matriciale di Thomson-Haskell e confrontandola con quelle osservate. La struttura del mantello superiore sotto Hyderabad mostra una zona di bassa velocità di circa $50 \mathrm{~km}$ di spessore, centrata ad una profondità approssimativa di circa $95 \mathrm{~km}$. Questo modello mostra una leggera diminuzione nella velocità delle onde $S$ e nella densità nella zona di bassa velocità, mentre la velocità delle onde $P$ rimane poco influenzata e continuamente crescente.

\footnotetext{
* National geophysical research institute, HYDERABAD 5.000 07, INDIA.
} 


\section{ABSTRACT}

The $P$ and $S$ waves spectra of three deep focus earthquakes, which occured at the sea of Okhotsk and Honshu, Japan regions and were recorded at Hyderabad seismograph station (HYB), India are used for the upper mantle structure determination. A new methodological procedure has been developped. Here, we take the vertical and horizontal components records of approximately 3 to 4 minutes duration and obtain the observed crustal transfer function using the application of a new data window. This data window enhances the signal by suppressing the noise in the desired frequency range of 0,02 to 0.18 . The crustal transfer function, obtained in this way using the data window, shows the similar trend with the transfer function obtained by taking the signal duration of smaller lenght i.e. when the signal lenght is free from later arrival of different phases like $P p, p P, P c P, P c S$, etc. The longer signal duration of 3 to 4 minutes lenght is sufficient to give the upper mantle structure down to a depth of about $400 \mathrm{~km}$. The theoretical transfer functions are obtained using the Thomson-Haskell matrix formulation and compared with the observed ones. The upper mantle velocity structure beneath Hyderabad shows a low velocity zone of about $50 \mathrm{~km}$ thickness centred at an approximate depth of about $95 \mathrm{~km}$. This model shows a slight decrease in the $S$-wave velocity and density in the low velocity zone, the $P$-wave velocity being very little affected and continuously increasing.

\section{INTRODUCTION}

A theoretical formulation for the determination of crust and upper mantle velocity structure using the body waves spectral data has been proposed by Kurita (1973). Later, Kurita (1974) determined the upper mantle structure down to about $220 \mathrm{~km}$ in the central United States using the $P$ and $S$ waves spectra of deep focus earthquakes recorded at three WWSSN stations. The theoretical aspect of this method was treated by Leblanc (1967), who used the truncated transfer function for the determination of fine crustal structure from the short period records. Kurita and Mikumo (1971) have used the $S$-waves spectral data and determined the crustal model. The determination of upper mantle velocity structure down to about $220 \mathrm{~km}$ requires the signal duration of the order of $120 \mathrm{sec}$. The main disadvantage in the longer signal duration is that it is contaminated by later phases, which produce noise. Kurita (1974) has used a combination of Fejer Kernel window and power window in his analysis to reduce 
this noise. In pour earlier paper. Singh and Rastogi (1978) have determined the crustal structure beneath Hyderabad, India, using the crustal transfer ratio of $P$ waves. Here, we have tried to determine the upper mantle velocity structure using the $P$ and $S$ waves transfer ratio. The existence of noise is reduced by applying a new data window in the observed crustal transfer ratio of $P$ and $S$ waves of 3 to 4 minutes duration.

\section{Data Analysis}

We examined the seismograms of Hyderabad seismic station for the period of 1971 to 1974 for the upper mantle velocity structure determination. Here we have got the recording of the three matched component long period, WWSSN type (Press Ewing) seismograph. We selected three deep focus earthquakes with fairly good recordings of $P$ and $S$ waves. The tracings of portion of seismograms are shown in Figure 1. The details of the earthquakes are given in Table 1. The arrival of various phases recorded in these earthquakes are given in Table II and also shown in Figure 1.'

The long period $P$ and $S$ waves of three earthquakes, shown in Figure 1, are digitized at the time interval of $0.8 \mathrm{sec}$ starting from the onset to sample lenght of 3 to 4 minutes duration. We have digitized our records with the help of WILD-AS Autograph.

\section{CRUSTAL TRANSFER FUNCTION RATIO}

The spectral ratio method is a valuable tool for the determination of crustal and upper mantle structure underlying a seismic station. The spectral ratio between the vertical and horizontal component records of the teleseismic $P$ and $S$ waves contain the information on the structure along the propagation path. Several parameters of crust and upper mantle like $P$ and $S$ wave velocity, density and thichness in each layer can be determined by this 


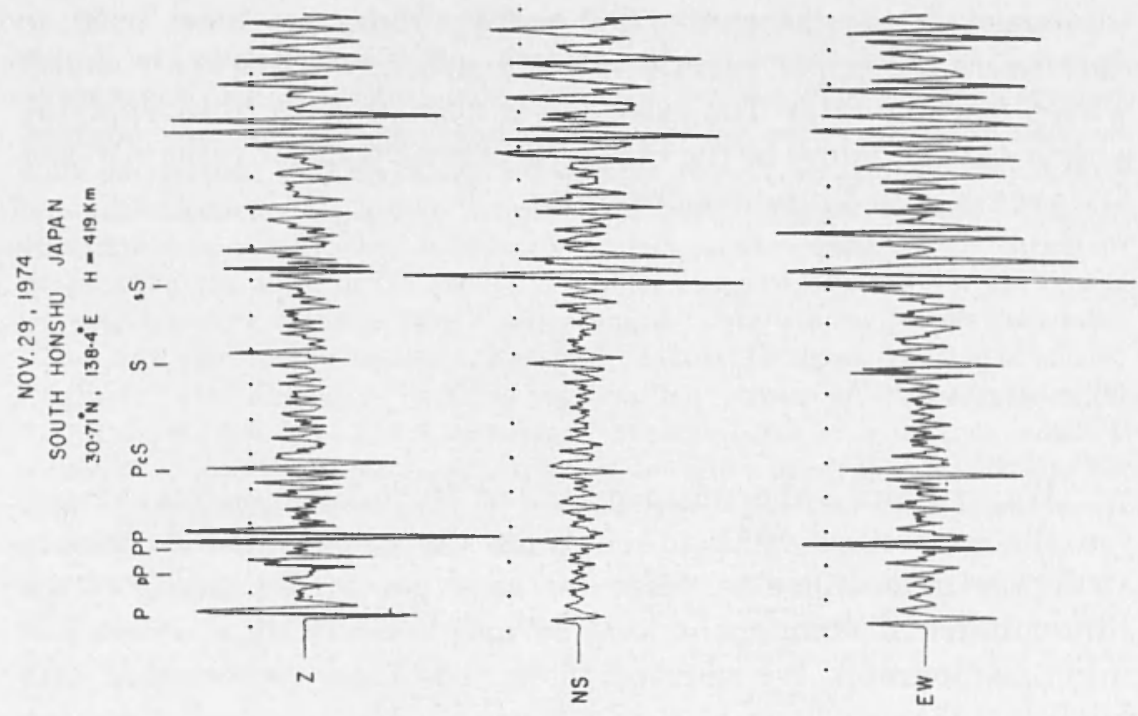

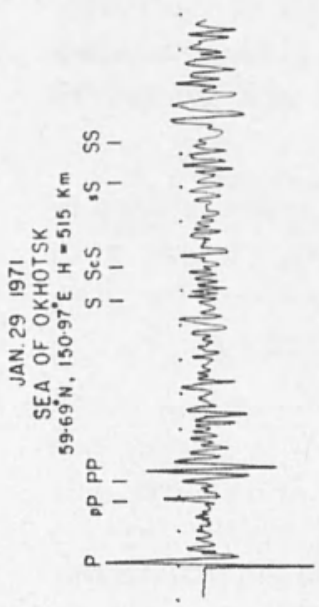

N
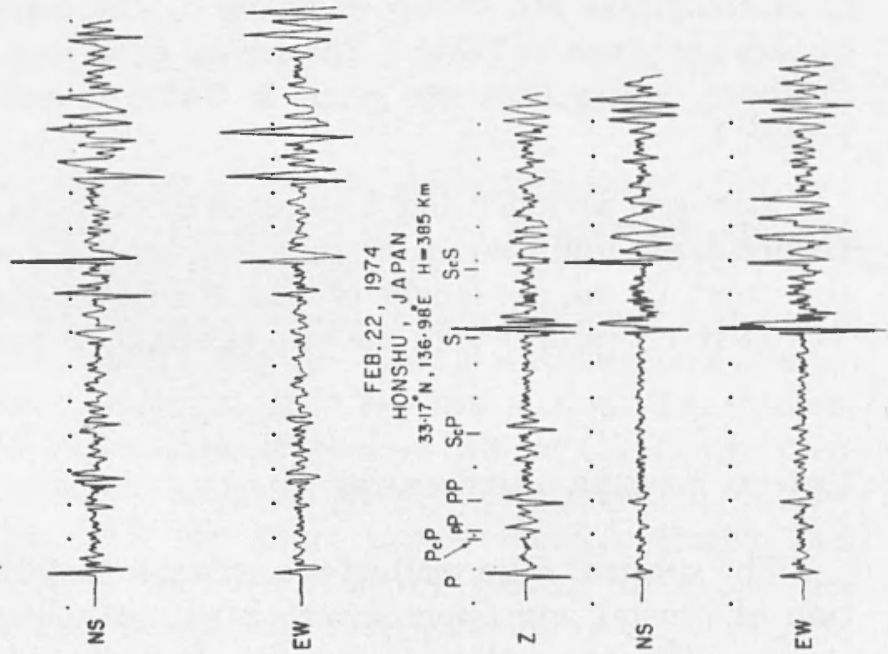

Fig. 1 - A portion of the seismograms of the long period vertical NS and EW component records by the Press-Ewing seismometers.

The small dots show the time marks in minutes. 


\section{TABLE I}

Details of the Earthquakes of which $P$ and $S$ waves are analyzed

\begin{tabular}{|c|c|c|c|}
\hline & 1 & 2 & 3 \\
\hline Date & Jan. 29, 1971 & Feb. 22,1974 & Nov. 29,1974 \\
\hline $\begin{array}{r}\text { Origin time } \\
\text { G.M.T. }\end{array}$ & 21: $58: 03.2$ & $00: 36: 53,8$ & 22: $05: 23.5$ \\
\hline $\begin{array}{c}\text { Focal dept } \\
\text { km }\end{array}$ & 515 & 385 & 419 \\
\hline Epicentre & $\begin{array}{c}59.69^{\circ} \mathrm{N}, 150.97^{\circ} \mathrm{E} \\
\text { Sea of Okhotsk }\end{array}$ & $\begin{array}{c}33.17^{\circ} \mathrm{N}, 136.98^{\circ} \mathrm{E} \\
\text { Honshu, Japan }\end{array}$ & $\begin{array}{c}30.71^{\circ} \mathrm{N}, 138.4^{\circ} \mathrm{E} \\
\text { South Honshu, Japan }\end{array}$ \\
\hline $\begin{array}{l}\text { Epicentral } \\
\text { distance, } \Delta \text {, degree }\end{array}$ & $65.65^{\circ}$ & $54.46^{\circ}$ & $55.69^{\circ}$ \\
\hline $\begin{array}{l}\text { Azimuth } \\
\text { degree (from epicentre } \\
\text { to station) }\end{array}$ & $267^{\circ}$ & $268^{\circ}$ & $217^{\circ}$ \\
\hline \multicolumn{4}{|l|}{$\begin{array}{l}\text { Angle of } \\
\text { incidence, degree }\end{array}$} \\
\hline$P$ & $37.0^{\circ}$ & $38.0^{\circ}$ & $38.2^{\circ}$ \\
\hline$s$ & $39.2^{\circ}$ & $37.2^{\circ}$ & $38.7^{\circ}$ \\
\hline
\end{tabular}


method. The spectral ratio of vertical, $V_{\mathrm{o}}(f)$ to horizontal motions, $H_{\mathrm{o}}(f)$, of the observd spectrum is given as

$$
\frac{V_{\mathrm{o}}(f)}{H_{\mathrm{o}}(f)}=\frac{S H_{s} M H_{v} I+N_{v}}{S H_{s} M H_{r} I+N_{H}}
$$

$$
\begin{aligned}
& \text { Where, } S \quad=\text { the earthquake source time function } \\
& H_{s} \quad=\text { Source crust - upper mantle transfer func- } \\
& \text { tion } \\
& M \quad \text { = Mantle transfer function due to the anelasti- } \\
& \text { city of the mantle } \\
& H_{v} ; H_{r} \quad=\text { Crust }- \text { Upper mantle transfer function at } \\
& \text { the station } \\
& \text { I } \quad \text { - Instrumental response function } \\
& N_{v}, N_{H} \quad=\text { Background noise level }
\end{aligned}
$$

For the noise free observations, $N_{v}$ and $N_{H}$ are zero and we have cancelled out the ratio of $S, H_{s}, M$ and $I$ for practical purpose in the vertical and horizontal spectra of wave motions (in the present study instrumental response is same for all the three components). In such cases, the ratio of vertical and horizontal components of crust-upper mantle transfer function at the station is expressed as:

$$
R_{\mathrm{o}}(f)=\frac{\stackrel{H}{-}_{v}}{\ddot{H}_{r}}
$$

The theoretical crust-upper mantle transfer function ratio is computed for various models using the Thomson-Haskell matrix formulation (Haskell, 1962). The observed transfer function ratio $R_{o}(f)$, is computed using the trace amplitude of $P$ and $S$ waves of 3 to 4 minutes duration of vertical (Z), NS and $E W$ component records and convolving a new data window. The longer signal duration contains noise part due to the inclusion of different phases of later arrivals. This effect is reduced by applying the data window. The digitized data of three components are multiplied by data window separately and then transformed in frequency do- 
main. The vertical component spectra $V_{0}(f)$, is obtained from vertical component record and $H_{\mathrm{o}}(f)$ is obtained by taking $N S$ and $E W$ component records, which will be discussed in later section. The observed transfer function ratio, computed using the $P$ or $S$ waves trace motion amplitudes of vertical, $N S$ and $E W$ components, is expressed as

$$
R_{\mathrm{o}}(f)=\left|\frac{\mathrm{V}_{o}(f) * W(f)}{H_{\mathrm{o}}(f) * W(f)}\right|
$$

Here, * denotes convolution and this is done for each individual components.

$V_{\mathrm{o}}(f)$ and $H_{\mathrm{o}}(f)$ are Fourier amplitudes of vertical and horizontal components of $P$ and $S$ wave trace motions, respectively. $W(f)$ is the frequency function of the selected data window and in time domain, this window is expressed as

$$
\begin{gathered}
\left.W(t)=\left(\mathrm{e}^{-t^{2}}-1\right)\left\{\frac{\sin ^{2}(t a / T)}{(t a / T)}+0.26 \cos t a / T\right)\right\} \\
\text { for } 0 \leqslant t \leqslant T \\
=0 \text { for } t<0, t>T
\end{gathered}
$$

Here,

$$
\begin{aligned}
& a=\text { constant (15 in the present case) } \\
& T \quad=\text { total length of the time-series data } \\
& t \quad=\text { data points generated for the time series }
\end{aligned}
$$

If $U\left(t_{k}\right) V\left(t_{k}\right)$ and $r\left(t_{k}\right)$ denote the $S$ pr $S$ wave trace motion amplitudes of vertical, $N S$ and $E W$ components, respectively, at certain time $t_{k}-k \Delta t(k=0,1,2, \ldots, N-1)$, the vertical and horizontal $P$ or $S$ wave amplitude spectra are expressed as

$$
\begin{gathered}
\left|V_{\mathrm{o}}(f)\right|=\quad \mid\left\{\sum_{k=0}^{N-1} U\left(t_{k}\right) \cos 2 \pi f k \Delta t\right\}^{2}+\left\{\sum_{k=0}^{N-1}\right. \\
\left.\left.U\left(t_{k}\right) \sin 2 \pi f k \Delta t\right\}^{2}\right]^{1 / 2}
\end{gathered}
$$




$$
\begin{gathered}
H_{\mathrm{o}}(f) \mid=\left[\left\{\sum_{k=0}^{N-1} h\left(t_{k}\right) \cos 2 \pi f k \Delta t\right\}^{2}+\right. \\
\left.+\left\{\sum_{k=0}^{N-1} h\left(t_{k}\right) \sin 2 \pi f k \Delta t\right\}^{2}\right] 1 / 2
\end{gathered}
$$

in the range of $0<f \leqslant f_{N}=1 / 2 \Delta t$ is the Nyquist frequency.

The horizontal trace amplitude $h\left(t_{k}\right)$ at any instant $t_{k}$ is determined using the relations (Leong, 1975):

$$
\begin{gathered}
\varphi_{k}=\arctan \left[r\left(t_{k}\right) / V\left(t_{k}\right)\right] \\
h\left(t_{k}\right)=V\left(t_{k}\right) / \cos \varphi_{k}
\end{gathered}
$$

The observed crustal transfer function ratio is determined using the above relation [3]. The summation in equations [5] and [6] is done using the Simpson's method. For the determination of observed transfer function, we multiplied the data window (relation [4]) with the digitized $P$ and $S$ wave trace amplitudes of vertical, NS and $E W$ components records. These data are then Fourier transformed using the Simpson's method to get the vertical and horizontal components spectral amplitudes. This has got the advantage over the Fast Fourier transform that we can get the amplitude spectrum at any desired frequency. Then these spectra are corrected for the instrumentl ffect using the relation given by Ben-Menahem et al (1968). Afterwards, the ratio of vertical and horizontal components spectral instrumental amplitudes; $\left|R_{\mathrm{o}}(f)\right|$, are obtained at different frequencies. For the selection of data window, we tried various type of data windows having different trigonometrical functions by trial and error and finally we get the preferred data winfow in the following way.

First we formed the observed crustal transfer function ratio without applying the data window from the digitized $P$ and $S$ waves trace amplitudes of selected sample lenght, such as 64,80 and $96 \mathrm{sec}$. The signal duration of these sample lenght contains $P$ or $S$ waves only and it is fre from noise. hose transfer ratios are shown in Figure 2 for different earthquakes. The change in the 

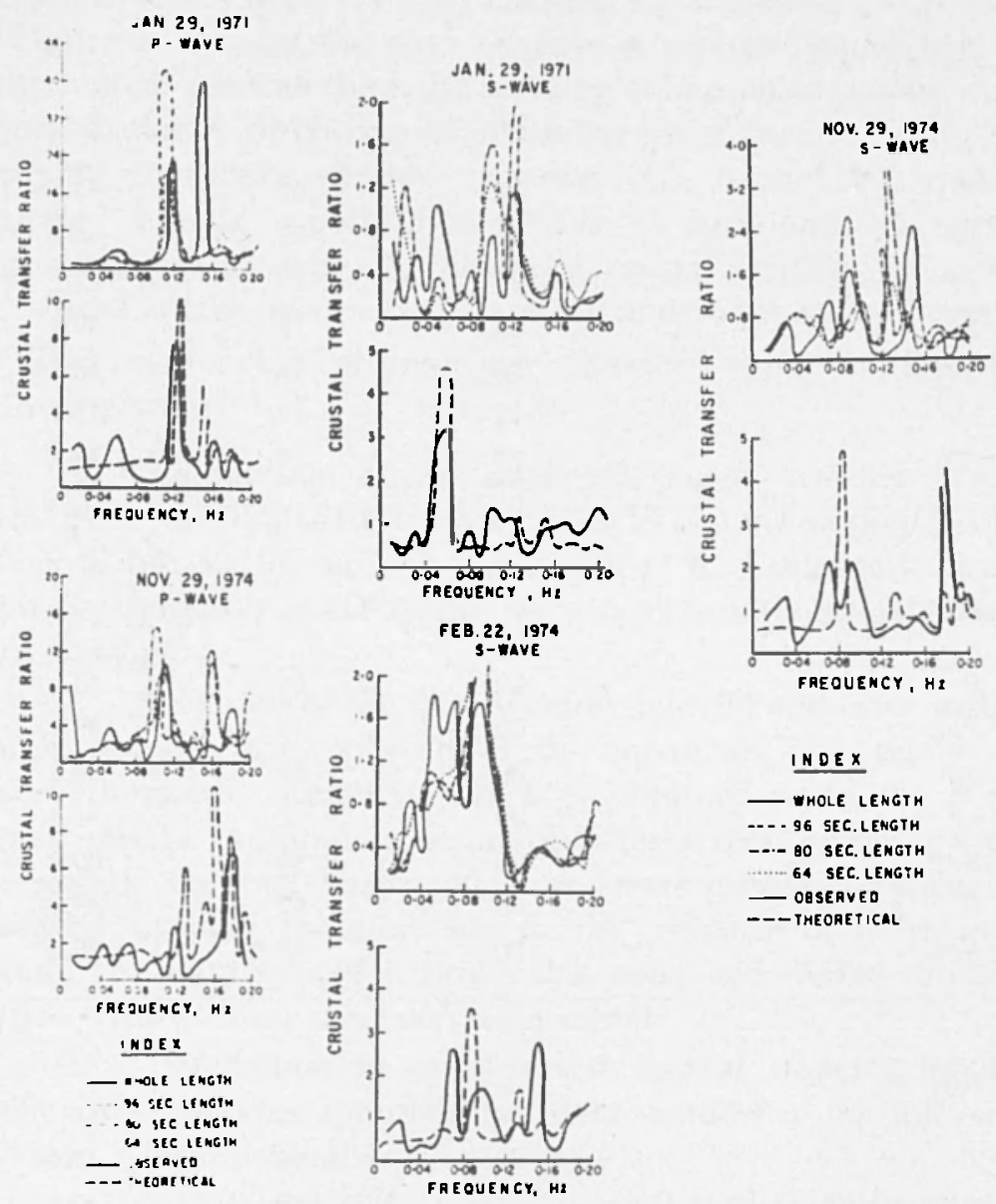

Fig. 2 - Comparison of the observed crustal transfer function ratios for different sample lenght of analysis with the theoretical computed transfer function ratios of $P$ and $S$ waves for the best fit model. 


\section{TABLE II}

Arrival times of different phases of the earthquakes

(1) Jan. 29, 1971

\begin{tabular}{lccc} 
& Hr. & Min. & Sec. \\
$P$ & 22 & 07 & 56.8 \\
$p P$ & 22 & 09 & 46.7 \\
$P P$ & 22 & 10 & 22.7 \\
$S$ & 22 & 15 & 59.8 \\
$S c S$ & 22 & 16 & 56.7 \\
$s S$ & 22 & 19 & 13.1 \\
$S S$ & 22 & 20 & 28.7 \\
\hline
\end{tabular}

(2) Feb. 22, 1974

\begin{tabular}{|c|c|c|c|}
\hline$P$ & 00 & 45 & 43 \\
\hline$P c P$ & 00 & 46 & 49.8 \\
\hline$p P$ & 00 & 47 & 03.0 \\
\hline$s P$ & 00 & 47 & 51.8 \\
\hline$S c P$ & 00 & 50 & 00.0 \\
\hline$S$ & 00 & 52 & 49.2 \\
\hline$S c S$ & 00 & 54 & 50.0 \\
\hline
\end{tabular}

(3) Nov. 29, 1974

$\begin{array}{llll}P & 22 & 14 & 17.4 \\ p P & 22 & 15 & 42.3 \\ P P & 22 & 16 & 26.3 \\ P c S & 22 & 18 & 28.3 \\ S & 22 & 21 & 30.3 \\ s S & 22 & 23 & 54.3\end{array}$


sample lenght does not atfect the peak position of the observed transfer ratio. We get the similar nature of the curve. As we use the full lenght of the signal some other phases like $P, P c P, s P, P P$, $s S$, etc. are also included. These form the noise part in the signal. The observed transfer ratio is charged for these signals as shown in Figure 2. We get the data window of relation [4] by trial and error, which reduces the noise level by enhancement of the signal. Figure 2 shows the observed crustal transfer function ratio after applying this data window (relation [4]) to the full lenght of digitized signals, usually 3 to 4 minutes duration. This curve is similar in nature with the observed crustal transfer ratio, when the signal is free from noise (i.e. 64, 80 and $96 \mathrm{sec}$ signal duration).

The methodological procedure described so far consists of the following steps:

1) - Calculation of the observed crustal transfer function ratio from the digitized trace amplitude of long period $P$ and $S$ waves of $64,80,96 \mathrm{sec}$ and full length ( 3 to 4 minutes) duration from the teleseismic deep focus earthquakes without applying the data window.

2) - Selection of the data window by trial and error method, which reduces the noise level by enhancing the signal. The observed transfer function, which is obtained using the $P$ or $S$ waves only i.e. without inclusion of latter arrival phases, contains the signal. The full lenght of wave forms changes the shape of observed transfer function due to the presence of noise in the signal. The data winow removes this noise and makes similar in nature with the case as observed in signal.

3) - Determination of observed crustal transfer function, $R_{\mathrm{o}}(f)$, after applying the preferred data window to the full lenght of $P$ and $S$ waves signals.

4) - Calculation of theoretical crustal transfer function ratio, $R_{T}(f)$, from some assumed model parameters using Thomson Haskell matrix formulation.

5) - Determination of upper mantle velocity structure at the recording station from the theoretical curve which matches the observed one, assuming the crustal model of Singh and Rastogi (1978). 


\section{Discussion}

Hyderabad lies in the central part of the Indian Peninsula. The triangle shaped Indian peninsula, slightly tilted eastward, occupies about two third area of the Indian subcontinent and it is one of the oldest blocks of the earth's crust and has maintained its continental character since Precambrian time. It is characterized by several mountain ranges, hills, rivers, deep broad valleys and plains of different elevations. The form of this plateau resembles a great triangle with its apex running into the Indian Ocean, between the Bay of Bengal in east and the Arabian Sea in west. The uppermost layer of this plateau consists of highly folded crystalline schists and Archean gneisses intruded by granite and granitic gneiss and widespread formations of metamorphosed igneous rocks. The crust and upper mantle structure of this important geological block has been investigated using the bodywaves travel time studies (Tandon and Chaudhury 1968; Kaila and Reddy, 1969) Arora et al., 1970; Dube et al. 1973) and using the surface-wave dispersion studies (Bhattacharya, 1974; Bhattacharya, 1981). Here, we have determined the upper mantle velocity structure beneath Hyderabad seismograph station down upto a depth of about $400 \mathrm{~km}$ using the $P$ and $S$ waves spectra. The upper mantle structure determination down upto this depth requires the signal duration of approximately 3 to 4 minutes.

The combined use of $P$ and $S$ wave crustal transfer function ratio as advantage that the reliability of model inferred from the $P$-wave spectra can be tested from the use of $S$ wave data also. As the transfer ratios for $P$ and $S$ waves have difference in nature and their spectral peaks position in different frequency range will vary. The use of longer signal duration of $P$ and $S$ waves will incorporate the background noise and it will sharpen the spectral peaks. Sometimes these spectral peaks will be combined into a single peak due to superimposition of several closely spaced peaks. The identification of correct spectral peaks corresponding to different frequency range is an important factor, while comparing the theoretical transfer ratio with the observed one. Figures 2 shows the observed crustal transfer function ratio computed using the relation mentioned earlier at the frequency interval of $0.005 \mathrm{~Hz}$ for 
TABLE III

Layer parameters and their possible range of variations below Moho

\begin{tabular}{|c|c|c|c|}
\hline $\begin{array}{l}\text { Thickness } \\
(\mathrm{km})\end{array}$ & $\begin{array}{c}\left(\mathrm{km}-\mathrm{sec}^{-1}\right) \\
\alpha\end{array}$ & $\begin{array}{c}\left(\mathrm{km}-\mathrm{sec}^{-1}\right) \\
\beta\end{array}$ & $\begin{array}{c}\left(\mathrm{gm}-\mathrm{cm}^{3}\right) \\
\rho\end{array}$ \\
\hline $48-68$ & $7.98-8.28$ & $4.65-4.85$ & $3.32-3.42$ \\
\hline $10-40$ & $8.13-8.33$ & $4.55-4.75$ & $3.30-3.40$ \\
\hline $10-40$ & $8.15-8.35$ & $4.50-4.70$ & $3.30-3.40$ \\
\hline $10-40$ & $8.10-8.30$ & $4.47-4.67$ & $3.30-3.40$ \\
\hline $45-75$ & $8.25-8.45$ & $4.50-4.70$ & $3.32-3.42$ \\
\hline $53-73$ & $8.45-8.65$ & $4.55-4.75$ & $3.35-3.45$ \\
\hline $5-35$ & $8.45-8.65$ & $4.60-4.80$ & $3.35-3.45$ \\
\hline $60-100$ & $8.55 \cdot 8.75$ & $4.65-4.85$ & $3.35-3.45$ \\
\hline $05-35$ & $8.60-8.80$ & $4.75-4.95$ & $3.56-3.76$ \\
\hline $08-38$ & $8.66-8.86$ & $4.80-4.90$ & $3.78-3.98$ \\
\hline$x$ & 9.10 & 5.00 & 3.90 \\
\hline
\end{tabular}

the $P$ and $S$ waves of earthquakes listed in Table I. We have assumed the crustal model of Singh and Rastogi (1978) and tried to find out the upper mantle model below Moho, which fits the observed transfer ratio well for $P$ and $S$ waves. A large number of models have to be considered for this purpose. The theoretical transfer function ratios have to be calculated for these models using the Thomson-Haskell matrix formulation and then compared with the observed one for the selection of the best fit model. It is arduous process. A large number of models have to be tested for this trial and error method. The layer parameters which have to be changed are the $P$ and $S$ wave velocities, density and thickness of each layer, as well as the angle of incidence. The angle of incidence of $P$ and $S$ waves does not vary much in the present study. For the thirteen layers earth model, the $P$ and $S$ waves velocities, density and layer thickness were taken in the range given in Table III. The velocities and density were varied with an increment of 0.10 units. The layer thickness of the individual layers were also varied in the suitable ranges. Similarly, we have also tried for seven, eight, nine and other different layers. The layer parameters of these models were taken from the ranges mentioned in Table III. We observed that more number of layers 


\begin{tabular}{|c|c|c|c|}
\hline $\begin{array}{l}\text { Thickness } \\
(\mathrm{Km})\end{array}$ & $\left(\mathrm{Km}^{\alpha} \mathrm{Sec}^{-1}\right)$ & $\left(k^{\beta} \sec ^{-1}\right)$ & ${\left.\stackrel{P}{g m} \mathrm{~cm}^{-3}\right)}^{-3}$ \\
\hline $20-23$ & $5 \cdot 81$ & $3 \cdot 12$ & $2 \cdot 68$ \\
\hline $8-10$ & $6 \cdot 41$ & $3 \cdot 62$ & $2 \cdot 75$ \\
\hline $7-9$ & $6 \cdot 66$ & $3 \cdot 94$ & $2 \cdot 91$ \\
\hline 58 & $8 \cdot 18$ & $4 \cdot 75$ & $3 \cdot 42$ \\
\hline 20 & $8 \cdot 23-8 \cdot 25$ & $4 \cdot 65$ & $3 \cdot 40$ \\
\hline 20 & $8 \cdot 23-8 \cdot 25$ & $4 \cdot 60$ & $3 \cdot 40$ \\
\hline 10 & $8 \cdot 20$ & $4 \cdot 57$ & $3 \cdot 40$ \\
\hline 65 & $8 \cdot 35$ & $4 \cdot 60-4 \cdot 62$ & $3 \cdot 42$ \\
\hline 63 & $8 \cdot 55$ & $4 \cdot 65$ & $3 \cdot 45$ \\
\hline 15 & $8 \cdot 55$ & $4 \cdot 70$ & $3 \cdot 45$ \\
\hline 90 & $8 \cdot 65$ & $4 \cdot 75$ & $3 \cdot 45$ \\
\hline 15 & $8 \cdot 70$ & $4 \cdot 85$ & $3 \cdot 66$ \\
\hline 18 & $8 \cdot 76$ & $4 \cdot 90$ & $3 \cdot 88$ \\
\hline$\infty$ & $9 \cdot 10$ & $5 \cdot 00$ & $3 \cdot 90$ \\
\hline
\end{tabular}

\section{SELECTED MODEL}

Fig. 3 - The layer parameters of the selected best fit velocity model.

give the better fit for both the $P$ and $S$ waves data. Some of the models selected give the better fit with the observed crustal transfer functions of $P$ or $S$ waves separately. When both the $P$ and $S$ waves data are combined several models are rejected because they do not give the better fit for the combined $P$ and $S$ waves transfer functions. There are only few models, which satisfied both $P$ and $S$ waves data simultaneously. In this way, the combination of $P$ and $S$ waves data have the advantages in selecting the better model for the upper mantle structure. However, the selected 
model cannot be considered as a unique model. This method does not give the unique selection of the best fit model. There may exist some models which will give rise to similar in nature of fitness, as in the present case. We have selected the best fit model (Figure 3 and 4) for thirteen layer upper mantle structure, which gives the best fit for both the observed $P$ and $S$ waves transfer functions by trial and error method mentioned earlier. The pronounced spectral peak positions corresponding to different frequency values for the observed $P$ and $S$ wave transfer function were matched with the theoretical one. In Figure 2, the lower portions show the comparison of observed crustal transfer function (i.e. when the noise effect has been removed from the signal after applying the data window for 3 to 4 minutes $P$ or $S$ wave signal duration) with the theoretical one computed for the best fit model. The observed $P$ wave transfer function ratio has two pronounced spectral peaks centred at the frequency 0.12 and $0.16-0.18 \mathrm{~Hz}$ and very little peak is showing at the frequency around $0.06 \mathrm{~Hz}$. The meaningful signal is obtained in the frequency range of 0.02 to $0.18 \mathrm{~Hz}$ and beyond this range noise effect due to later arrivals of different phases, lateral variations in the layering, crustal reverberation, ground noise, etc. effect the signal. The signal/noise ratio of $P$ wave is high for the earthquake of January 29, 1971 and we obatin good fit. For the other earthquakes, the $P$ wave signal is very weak as compared to noise (Figure 1) and signal/noise ratio is very poor we do not get better fit. The observed transfer ratio for $S$ waves is showing pronounced spectral peak around frequency of $0.08 \mathrm{~Hz}$. The theoretical spectral ratio for $S$ wave shows good fit with the observed data for earthquakes of February 23, 1974 and January 29,1971 . The spectral peaks in the observed transfer ratio of $S$ waves for Febraury 22, 1974 earthquake has shifted towards the lower frequency side. The pronounced spectral peak at a frequency around $0.18 \mathrm{~Hz}$ for November 29, 1974 earthquake is seen for $S$-wave observed transfer function. This may be due to the poor signal/noise ratio.

Figure 4 shows the comparison of CANSD model (Brune and Dorman, 1963) with the layer parameters of the present model. Both the models have been derived from the regions of shield area. There is much similarity in the nature of the layer parameters of 


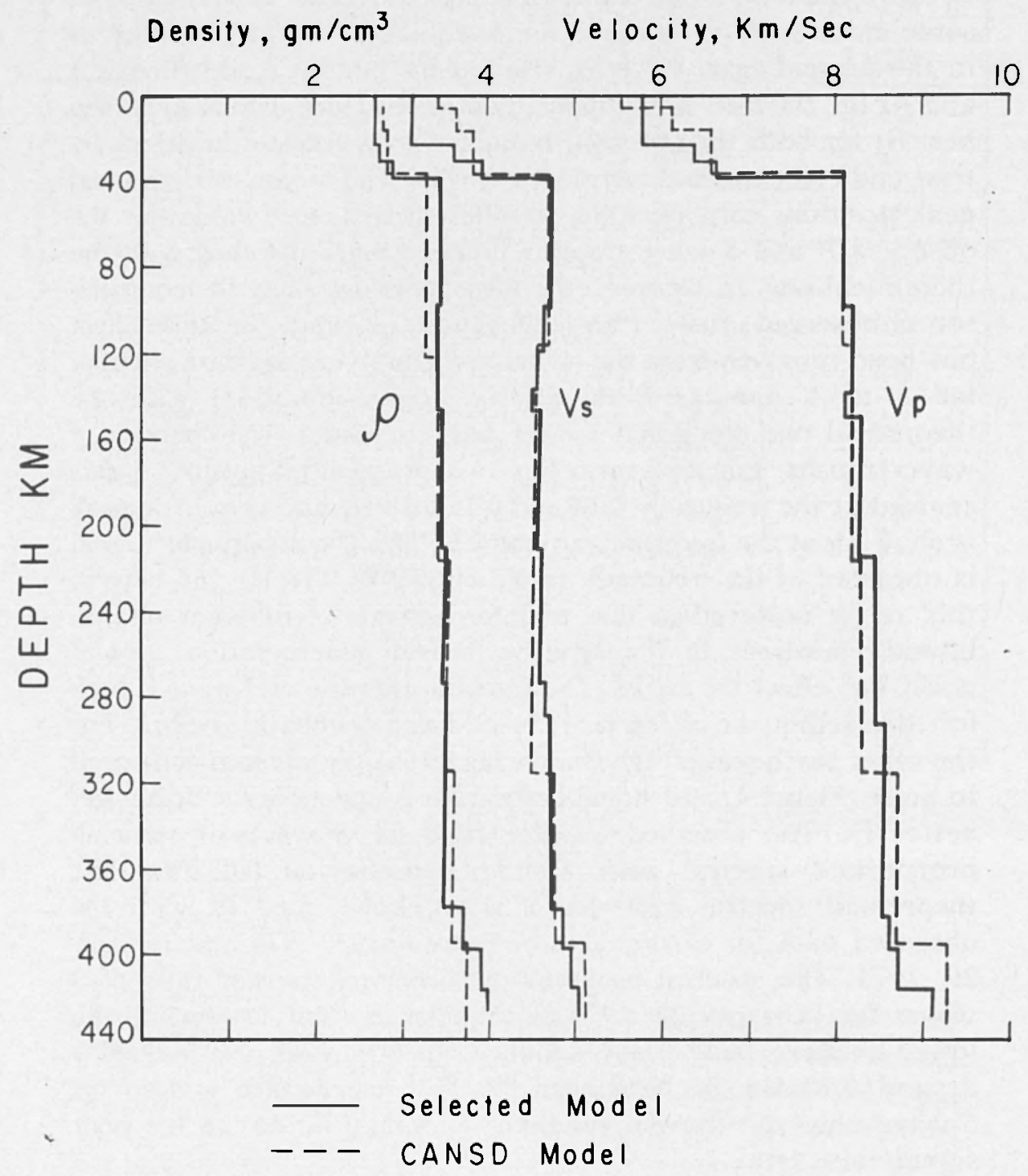

Fig. 4 - Comparison of the preferred velocity model with CANSD model. 
both the models. The present selected model shows a low velocity zone (LVZ) of $50 \mathrm{~km}$ thickness centred at a depth of around $95 \mathrm{~km}$. We have also tried with higher velocities and density, but the fit was not satisfactory with the observed and theoretical transfer functions. An attempt was also made by taking the greater thickness of LVZ, but the fit was not good.

\section{Conclusions}

The comparison of observed crustal transfer function ratios of $P$ and $S$ waves for three deep focus earthquakes with theoretical one gives the upper mantle velocity structure below Hyderabad region. This model shows a low velocity zone of $50 \mathrm{~km}$ thickness centred at a depht of about $95 \mathrm{~km}$. There is a slight decrease in the $S$-wave velocity and density in the LVZ, whereas the $P$-wave velocity is very little effected and is continuously increasing.

\section{AcKNOWLedgements}

The facilities provided by Survey of India, Hyderabad for digitizing the records is gratefully acknowledged. I thank Director, National Geophysical Research Institute, Hyderabad, India for according permission to publish this work. Mr. K. Ramana Rao and Miss A. Suhasini assisted in the preparation of the manuscript. 


\section{REFERENCES}

ARORA, S.K., VARGHESE, T.G. and KRISHNA, C.A., 1970 - Some aspects of the structure of Southern India based on recent Bhadrachalam earthquakes, "Nature", 225, pp. 261-262.

Ben-Menahem, A., Jarosh, H., and Roseman, M., 1968 - Large scale processing of seismic data in search of regional and global stress patterns. "Bull. Seismol. Soc. Am.", 58, pp. 1899-1932.

BhatTaChaRYA, S.N., 1974 - The crust mantle structure of the Indian Peninsula from surface wave dispersion. "Geophys. J.R. Astron. Soc.", 36, pp. 273-283.

BhatTACHARYA, S.N., 1981 - Obsenvation and inversion of surface wave group velocities across central India. "Bull. Seismol. Soc. Am", 71, pp. 1489-1501.

Brune, J., and Dorman, J., 1963 - Seismic waves and earth structure in the Canadian shield, "Bull. Seismol. Soc. Am.", 53, pp. 167-210.

Dube, R.K. Bhayana, J.G., and Chaudhury, H.M., 1973 - Crustal structure of the Peninsular India. "Pure Appl. Geophys.", 109, pp. 1718-1727.

HASKeLL, N.A., 1962 - Crustal reflection of plane P and SV waves. "J. Geophys. Res.", 67, pp. 4751-4767.

KAILA, K.L., and REDDY, P.R., 1969 - Crustal structure in India, "Ann. Rep. National Geophys. Res. Inst.", 1967-68, pp. 24-26.

KURITA, T., 1973 - A procedure for elucidating fine structure of the crust and upper mantle from seismological data. "Bull. Seismol. Soc. Am.", 63, pp. 189-209.

KURITA, T, 1974 - Upper-mantle structure in the central United States from P-and Swave spectra. "Phys. Earth Planet. Interiors", 8, pp. 117-201.

LEBLANC, G.S.J., 1967 - Truncated crustal transfer functions and fine crustal structure determination. "Bull. Seismol. Soc. Am.", 57, pp. 719-733.

LEONG, L.S. 1975 - Crustal structure of the Baltic shield beneath Umea, Sweden, from the spectral behaviour of long-period P-waves, "Bull. Seismol. Soc. A.", 65. pp. 113-126.

SINGH, D.D., and RASTOGI, B.K., 1978 - Crustal structure of the peninsular shield beneath Hyderabad (India) from the spectral characteristics of long period P-waves. "Tectonophysics", 65, pp. 127-137.

TANDON, A.N., and Chaudhury, H.M., 1968 - Kyona earthquake of December, 1967. “Sci. Rep. Ind. Met. Dept.", No. 59, pp. 1-12. 